\title{
Prognostic values of tumoral MMP2 and MMP9 overexpression in breast cancer: a systematic review and meta-analysis
}

\author{
Hanfang Jiang and Huiping Li* (D)
}

\begin{abstract}
Background: Breast cancer (BC) is a leading cause of cancer-related death in females worldwide. Previous studies have demonstrated that matrix metalloproteinases (MMPs) play key roles in metastasis and are associated with survival in various cancers. The prognostic values of MMP2 and MMP9 expression in BC have been investigated, but the results remain controversial. Thus, we performed the present meta-analysis to investigate the associations between MMP2/9 expressions in tumor cells with clinicopathologic features and survival outcome in BC patients.

Methods: Eligible studies were searched in PubMed, Web of Science, EMBASE, CNKI and Wanfang databases. The associations of MMP2/9 overexpression in tumor cells with overall survival (OS), disease-free survival (DFS) and recurrence-free survival (RFS) were assessed by hazard ratio (HR) and $95 \%$ confidence interval (Cl). The associations of MMP2/9 overexpression with clinicopathological features were investigated by calculating odds ratio (OR) and 95\% Cl. Subgroup analysis, sensitivity analysis, meta-regression, and analysis for publication bias were performed.

Results: A total of 41 studies comprising 6517 patients with primary BC were finally included. MMP2 overexpression was associated with an unfavorable OS ( $\mathrm{HR}=1.60,95 \% \mathrm{Cl} 1.33-1.94, P<0.001)$ while MMP9 overexpression predicted a shorter OS (HR $=1.52,95 \% \mathrm{Cl} 1.30-1.77, P<0.001)$. MMP2 overexpression conferred a higher risk to distant metastasis $(\mathrm{OR}=2.69,95 \% \mathrm{Cl} 1.35-5.39, P=0.005)$ and MMP9 overexpression correlated with lymph node metastasis $(\mathrm{OR}=2.90,95 \% \mathrm{Cl} 1.86-4.53, \mathrm{P}<0.001)$. Moreover, MMP2 and MMP9 overexpression were both associated with higher clinical stage and histological grade in BC patients. MMP9 overexpression was more frequent in patients with larger tumor sizes.
\end{abstract}

Conclusions: Tumoral MMP2 and MMP9 are promising markers for predicting the prognosis in patients with BC.

Keywords: Breast cancer, MMP2, MMP9, Survival, Meta-analysis

\section{Background}

Breast cancer $(\mathrm{BC})$ is the most prevalent malignancy and one of the leading causes of cancer-related death among females worldwide [1]. It accounts for $24.2 \%$ of newly diagnosed cancer cases and $15.0 \%$ of death from cancer in women [1]. Furthermore, the incidence and mortality

\footnotetext{
* Correspondence: lihuiping@bjcancer.org

Key Laboratory of Carcinogenesis and Translational Research (Ministry of Education/Beijing), Department of Breast Oncology, Peking University Cancer Hospital \& Institute, No. 52nd Fucheng Road, Haidian District, Beijing 100142, China
}

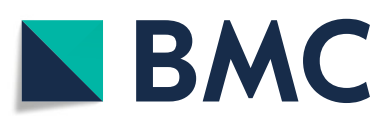

( The Author(s). 2021 Open Access This article is licensed under a Creative Commons Attribution 4.0 International License, which permits use, sharing, adaptation, distribution and reproduction in any medium or format, as long as you give appropriate credit to the original author(s) and the source, provide a link to the Creative Commons licence, and indicate if changes were made. The images or other third party material in this article are included in the article's Creative Commons licence, unless indicated otherwise in a credit line to the material. If material is not included in the article's Creative Commons licence and your intended use is not permitted by statutory regulation or exceeds the permitted use, you will need to obtain permission directly from the copyright holder. To view a copy of this licence, visit http://creativecommons.org/licenses/by/4.0/. The Creative Commons Public Domain Dedication waiver (http://creativecommons.org/publicdomain/zero/1.0/) applies to the data made available in this article, unless otherwise stated in a credit line to the data. rates of $\mathrm{BC}$ have been increasing in recent years [2]. Previous studies have identified metastasis, tumor stage, histological grade, expression of estrogen receptor (ER), progesterone receptor $(\mathrm{PR})$, and human epidermal growth factor receptor 2 (HER2) as prognostic factors for BC [3]. The significant findings of these biomarkers have promoted the development of molecular-targeted therapy of BC [4]. Therefore, identifying more and more molecular biomarkers would definitely improve the treatment and management of $\mathrm{BC}$ in the future. 
Matrix metalloproteinases (MMPs) are a group of zinc endopeptidases critical for the decomposition of extracellular matrix (ECM) components and basement membrane (BM) [5]. MMPs thus play pivotal roles in various physiological and pathological processes, including morphogenesis, wound healing, inflammation, cancer invasion, and metastasis [6]. MMPs are structurally divided into several subtypes, among which MMP2 and MMP9 belong to the gelatinase family that mainly degrades gelatin, collagens IV and V in ECM and BM through their proteolytic function [7]. In cancer, the overproduction or increased activity of MMP2/9 leads to the degradation of ECM and BM, allowing for the invasion of tumor cells to other tissues and tumor cell metastasis to distant organs [8]. MMP2/9 have also been implicated in cancer development and progression through their functions in cell apoptosis, proliferation, and angiogenesis [9-11].

Previous studies demonstrated that MMP2/9 are important prognostic factors for various cancers. MMP2 and MMP9 overexpression was associated with poor prognosis in oral cancers [12], retinoblastoma [13], bladder cancer [14], and ovarian epithelial cancer [15]. The prognostic value of MMP2/9 in BC has also been investigated. Several studies reported that MMP2/9 overexpression was related to clinicopathological characteristics and associated with poor survival in patients with $\mathrm{BC}$ [16-19], indicating that MMP2/9 may function as good prognostic markers for BC. However, other studies showed no associations of MMP2/9 overexpression with survival [2023]. Thus, the associations between MMP2/9 expression and clinicopathological features and survival in $\mathrm{BC}$ remain controversial.

To evaluate the prognostic values of MMP2/9 in BC, we performed a meta-analysis for the associations between MMP2/9 overexpression in tumor cells with the clinicopathologic features and survival outcomes in BC patients.

\section{Methods}

\section{Literature search strategy}

This was a Preferred Reporting Items for Systematic Reviews and Meta-Analysis (PRISMA) statement based meta-analysis [24]. A comprehensive literature search was performed in PubMed, Web of Science, EMBASE, CNKI and Wanfang databases from study inception to June 30, 2020. The following search terms were used: (breast cancer OR breast tumor OR breast neoplasm OR breast carcinoma) AND (matrix metalloproteinase OR MMP2 OR MMP9 OR gelatinase). There was no language restriction. References in relevant articles were furtherly scanned for more potentially eligible studies.

\section{Inclusion and exclusion criteria}

Studies that met the following criteria were included: 1) detecting the protein expression of MMP2 and/or MMP9 in tumor cells of breast cancer tissue by immunohistochemistry (IHC); 2) investigating the associations between MMP2/MMP9 overexpression and survival and/or clinicopathological features; 3) reporting hazard ratio (HR) with corresponding 95\% confidence interval (CI) or survival curves for survival analysis, or providing sufficient data to calculate the odds ratio (OR) with 95\% CI for clinicopathological features. Studies that measured mRNA expression or protein levels in serum or stromal cells were excluded. Reviews, meta-analyses and studies lacking sufficient data were excluded. If several studies had overlapping samples, only the largest one was included.

\section{Data extraction and quality assessment}

The following data were extracted by two independent researchers: first author, publication year, country, sample size, follow-up duration, percent of infiltrating ductal carcinoma (IDC), criteria for MMPs overexpression, survival outcomes, HR and 95\% CI, clinicopathological features, tissue and antibody used for IHC staining, and the data for the calculation of OR and 95\% CI. The quality of included studies were assessed by Newcastle-Ottawa Scale (NOS), which assigned a total of 9 stars to 8 items [25]. Studies awarded 6 or more stars were considered as high quality. The literature search, selection, data extraction and quality assessment were performed by two independent researchers (HJ and HL). Discrepancies were resolved by discussion.

\section{Definition of MMP2/MMP9 overexpression}

MMP2/MMP9 overexpression in tumor sections was assessed using specific cut-offs of percentage of stained cells or the stained index (SI) that combines both percentage and intensity of staining, or the other methods. The SI was calculated as either the sum or product of staining percentage and intensity scores or determined using other complex scoring methods.

\section{Survival outcomes}

The survival outcomes we investigated included overall survival (OS), disease-free survival (DFS), and recurrence-free survival (RFS). We obtained HR and 95\% CI from univariate and/or multivariate analysis of associations between MMP2/MMP9 overexpression and survival. If no HR data were reported, we extracted survival data from the survival curves by using Engauge Digitizer software (https://github. $\mathrm{com} /$ markummitchell/engauge-digitizer) and estimated the HR and $95 \%$ CI by using the method by Tierney et al [26]. If a study reported HRs from both univariate and multivariate analysis, the latter was included in the overall analysis, 
and both were included in the subgroup analysis of univariate or multivariate analysis, respectively.

\section{Clinicopathological features}

The clinicopathological features investigated in our analysis included tumor size, lymph node metastasis, distant metastasis, estrogen receptor (ER) status, progesterone receptor (PR) status, human epidermal growth factor receptor 2 (HER2) status, TNM stage, and histological grade, as those are associated with the prognosis of $\mathrm{BC}$.

\section{Statistical analysis}

Between-study heterogeneity was determined by using $\mathrm{I}^{2}$ and Q test. If $\mathrm{I}^{2}$ was $50 \%$ and $P$ value for $\mathrm{Q}$ test was > 0.10 , a fixed-effect model was used. Otherwise, a random-effect model was used. For survivals, pooled HR and $95 \% \mathrm{CI}$ were calculated, and subgroup analyses regarding ethnicity (Caucasians, Asians), IHC analysis standard (percentage, SI, other cut-offs), HR data source (reported, estimated), analysis model (univariate, multivariate), sample size, cancer subtype, tissue (whole tissue, tissue microarray), IHC antibody (monoclonal, polyclonal) and antibody source (mouse, rabbit) were performed. For clinicopathological features, pooled OR and 95\%CI were calculated, and subgroup analyses were also performed. Sensitivity analysis and meta-regression were performed to find the potential source of heterogeneity. Publication bias was assessed by funnel plot and Egger's test. All the analyses were performed by using STATA 12.0 (Stata Corporation, TX, USA). $P<0.05$ was considered statistically significant.

\section{Results}

\section{Description of eligible studies}

The literature search yielded a total of 68 studies for full-text reviewing. Then, 27 studies were excluded as they detected MMP2/MMP9 expression in serum $(n=$ $17)$ or cytosol tumor extracts $(n=1)$ or in stromal cells $(n=1)$, investigated mRNA expression $(n=4)$, duplicated with others $(n=4)$. Finally, a total of 41 studies comprising 6517 patients with primary breast cancers [16-23, 27-59] were included in our meta-analysis (Fig. 1). Among them, 31 studies with 4895 patients were eligible for survival analysis and 30 studies with 4743 cases for the analysis of clinicopathological features. The sample sizes range from 41 to 675. Regarding ethnicity, 22 studies were conducted in Caucasian populations and 19 in Asian populations. Regarding the definition of overexpression, 19 studies used percentage criteria, 19 used SI criteria and 3 used the other criteria [5759]. According to NOS, 12 studies had 6 stars, 20 had 7 stars and 9 had 8 stars, indicating that all studies were of high quality.

For survival analysis, the HR and 95\% CI were estimated from survival curves in 10 studies and were directly reported in 21 studies. Overexpression of MMP2

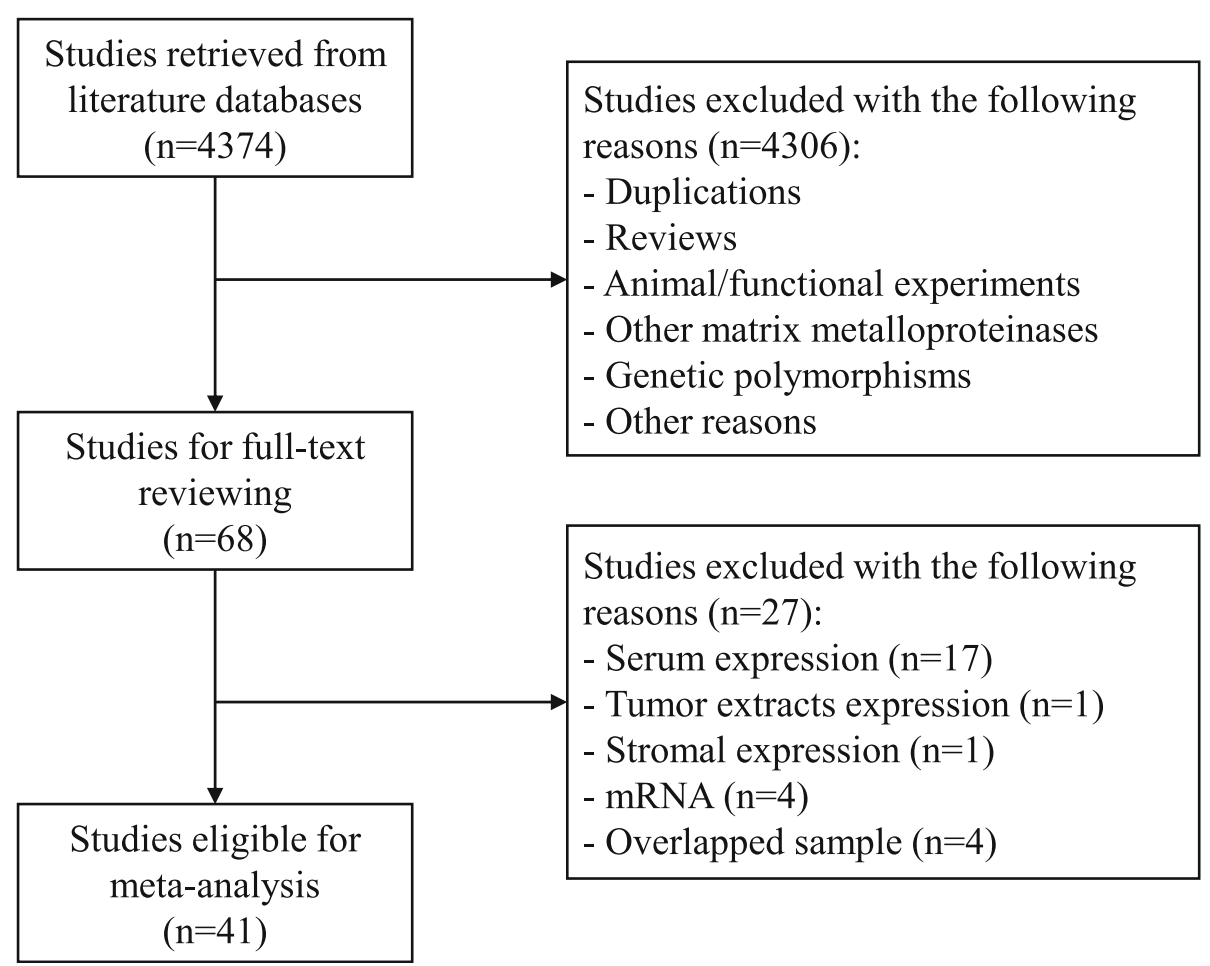

Fig. 1 Flowchart of literature search and selection of eligible studies 
and MMP9 were investigated in 17 and 21 studies, respectively. The associations between MMP2 and MMP9 overexpression and clinicopathological features were reported in 14 and 20 studies, respectively. The characteristics of survival analysis and clinicopathological features were summarized in Table 1 and Table 2, respectively. The primary anti-huamn-MMP2/9 antibody used for IHC staining varied between studies and was summarized in Table S1.

\section{MMP2 overexpression and survival}

As shown in Table 3, there were no significant associations between MMP2 overexpression with DFS (HR = $1.79, P=0.096)$ or RFS $(\mathrm{HR}=1.21, P=0.338)$ in $\mathrm{BC}$. However, after pooling 14 studies, patients with MMP2 overexpression showed an unfavorable $\mathrm{OS}(\mathrm{HR}=1.60$, 95\% CI 1.33-1.94, $P<0.001$, Fig. 2). The association was significant regarding ethnicity, IHC analysis standard, sample size and the anti-human-MMP2 antibody used

Table 1 Characteristics of eligible studies for survival analysis

\begin{tabular}{|c|c|c|c|c|c|c|c|c|c|c|c|}
\hline Author & Year & Country & $\begin{array}{l}\text { Sample } \\
\text { size }\end{array}$ & $\begin{array}{l}\text { Percent of } \\
\text { IDC (\%) }\end{array}$ & Cut-off $^{a}$ & Follow-up & Protein & $\begin{array}{l}\text { Survival } \\
\text { outcome }\end{array}$ & $\begin{array}{l}\text { HR } \\
\text { data }\end{array}$ & $\begin{array}{l}\text { Survival } \\
\text { analysis }\end{array}$ & $\overline{\text { NOS }}$ \\
\hline Talvensaari-Mattila [51] & 1998 & Finland & 169 & 82 & $P>0 \%$ & 92 months & MMP2 & OS & Rep & U & 8 \\
\hline Talvensaari-Mattila [50] & 1999 & Finland & 108 & 96 & $P>0 \%$ & 2 years & MMP2 & RFS & Est & U & 8 \\
\hline Talvensaari-Mattila [49] & 2001 & Finland & 100 & 79 & $P>0 \%$ & 44 months & MMP2 & OS, RFS & Est & $U$ & 7 \\
\hline Scorilas & 2011 & Greece & 210 & 75 & HSCORE $>175$ & 62 months & MMP9 & OS, RFS & Rep & $U, M$ & 7 \\
\hline Djonov [48] & 2002 & Switzerland & 75 & 61 & $\mathrm{SI} \geq 1$ & $N R$ & MMP2 & OS, DFS & Rep & $M$ & 6 \\
\hline Hirvonen [47] & 2003 & Finland & 137 & $N R$ & $P>0 \%$ & 10 years & MMP2 & RFS & Est & $U$ & 6 \\
\hline Fan [45] & 2003 & China & 66 & 86 & $\mathrm{SI} \geq 1$ & 30.5 months & MMP2, MMP9 & OS & Rep & M & 6 \\
\hline Talvensaari-Mattila [44] & 2003 & Finland & 453 & 75 & $P>0 \%$ & 60-150 months & MMP2 & OS & Rep & M & 8 \\
\hline Li [19] & 2004 & China & 270 & 90 & $P>0 \%$ & 61 months & MMP2, MMP9 & OS, RFS & Rep & $U, M$ & 6 \\
\hline Pellikainen [58] & 2004 & Finland & 415 & 64 & $P>85 \%^{b}$ & 55 months & MMP9 & RFS & Rep & $M$ & 7 \\
\hline Rahko [23] & 2004 & Finland & 168 & 75 & $P>1 \%$ & 7-111 months & MMP9 & OS, DFS & Rep & $U$ & 7 \\
\hline Ban [52] & 2004 & China & 60 & 100 & $\mathrm{SI} \geq 3$ & $>5$ years & MMP2 & OS & Est & U & 7 \\
\hline Zhou [42] & 2005 & China & 112 & 84 & $P>5 \%$ & 48 months & MMP2 & OS & Rep & $M$ & 7 \\
\hline Zhang [38] & 2008 & China & 263 & 100 & $\mathrm{SI} \geq 6$ & 92.1 months & MMP2, MMP9 & OS & Rep & U & 6 \\
\hline Zhao [53] & 2008 & China & 71 & 93 & $P>10 \%$ & 54.94 months & MMP9 & OS & Est & U & 6 \\
\hline Sullu [22] & 2011 & Turkey & 140 & 100 & $S I \geq 5$ & 63.2 months & MMP9 & OS, DFS & Est & U & 8 \\
\hline Ranogajec [37] & 2012 & Croatia & 138 & 59 & $\mathrm{SI} \geq 2$ & 5 years & MMP2 & OS & Est & U & 7 \\
\hline Fernandez-Guinea [21] & 2013 & Spain & 97 & 100 & $\mathrm{SI}$ & $>5$ years & MMP2, MMP9 & RFS & Rep & $U, M$ & 6 \\
\hline Zhao [18] & 2013 & China & 127 & NR & $S I \geq 6$ & NR & MMP9 & OS & Rep & M & 6 \\
\hline Liu [17] & 2013 & China & 189 & 89 & $P>10 \%$ & NR & MMP9 & OS & Rep & $U, M$ & 8 \\
\hline Zeng [36] & 2013 & China & 253 & $N R$ & $P>20 \%$ & 15 years & MMP9 & OS, DFS & Rep & $U, M$ & 8 \\
\hline Merdad [20] & 2014 & Saudi Arabia & 45 & 84 & $\mathrm{SI} \geq 2$ & 52.1 months & MMP9 & OS & Rep & $U$ & 7 \\
\hline Puzovic [35] & 2014 & Croatia & 121 & 100 & $\mathrm{SI}$ & 80.6 months & MMP2, MMP9 & OS, DFS & Rep & U & 7 \\
\hline Min [32] & 2014 & Korea & 177 & 100 & $\mathrm{SI} \geq 1, \mathrm{SI} \geq 5$ & NR & MMP2, MMP9 & OS & Rep & M & 7 \\
\hline Yousef [30] & 2014 & Canada & 300 & $N R$ & $S I \geq 5$ & $N R$ & MMP9 & RFS & Est & U & 6 \\
\hline Bottino [59] & 2014 & Brazil & 60 & 1 & MOD> 191 & $N R$ & MMP9 & OS & Rep & U & 7 \\
\hline Huang [55] & 2014 & China & 147 & 86 & $P>10 \%$ & 45.6 months & MMP9 & OS, DFS & Rep & $U, M$ & 6 \\
\hline Ramos [29] & 2016 & Brazil & 44 & 77 & $P>10 \%$ & $N R$ & MMP2 & OS, DFS & Est & $U$ & 7 \\
\hline Li [16] & 2017 & China & 80 & $N R$ & $P>25 \%$ & $N R$ & MMP2, MMP9 & OS & Est & U & 7 \\
\hline Yang [28] & 2018 & Korea & 173 & 100 & $\mathrm{SI} \geq 2$ & NR & MMP9 & OS, DFS & Rep & $U, M$ & 8 \\
\hline Zhang [56] & 2019 & China & 127 & $N R$ & $S I \geq 6$ & $N R$ & MMP9 & OS & Rep & $M$ & 7 \\
\hline
\end{tabular}

${ }^{a}$ Cut-off for overexpression of matrix metalloproteinases in tumor cells by immunohistochemistry

${ }^{\mathrm{b}}$ Median value

IDC infiltrating ductal carcinoma, $P$ percentage of stained cells, SI staining index considering both percentage and intensity of staining, OS overall survival, DFS disease-free survival, RFS recurrence-free survival, Rep reported in the text, Est estimated from survival curve, $U$ univariate analysis, $M$ multivariate analysis, NR not reported, $M O D$ mean optical density 
Table 2 Characteristics of eligible studies for clinicopathological features

\begin{tabular}{|c|c|c|c|c|c|c|c|c|c|c|c|c|c|c|}
\hline Author & Year & Country & Sample size & Cut-off $^{\mathrm{a}}$ & Protein & $\mathbf{T}$ & $\mathrm{N}$ & $M$ & ER & PR & HER2 & $S$ & G & NOS \\
\hline Talvensaari-Mattila [51] & 1998 & Finland & 169 & $P>1 \%$ & MMP2 & $\checkmark$ & $\checkmark$ & $\checkmark$ & $\checkmark$ & $\checkmark$ & & $\checkmark$ & $\checkmark$ & 8 \\
\hline Talvensaari-Mattila [50] & 1999 & Finland & 108 & $P>1 \%$ & MMP2 & $\checkmark$ & & & $\checkmark$ & $\checkmark$ & & & $\checkmark$ & 8 \\
\hline Talvensaari-Mattila [49] & 2001 & Finland & 100 & $P>1 \%$ & MMP2 & $\checkmark$ & & & & & & & $\checkmark$ & 7 \\
\hline Scorilas & 2011 & Greece & 210 & HSCORE $>175$ & MMP9 & $\checkmark$ & $\checkmark$ & & $\checkmark$ & $\checkmark$ & & $\checkmark$ & $\checkmark$ & 7 \\
\hline Hirvonen [47] & 2003 & Finland & 137 & $P>1 \%$ & MMP2 & $\checkmark$ & & & $\checkmark$ & $\checkmark$ & & $\checkmark$ & & 6 \\
\hline Nakopoulou & 2003 & Greece & 135 & $P>10 \%$ & MMP2 & $\checkmark$ & & & $\checkmark$ & $\checkmark$ & & $\checkmark$ & & 6 \\
\hline Fan [45] & 2003 & China & 66 & $\mathrm{SI} \geq 1$ & MMP2, MMP9 & $\checkmark$ & $\checkmark$ & & $\checkmark$ & $\checkmark$ & & $\checkmark$ & & 6 \\
\hline Talvensaari-Mattila [44] & 2003 & Finland & 453 & $P>1 \%$ & MMP2 & $\checkmark$ & $\checkmark$ & $\checkmark$ & $\checkmark$ & $\checkmark$ & & & $\checkmark$ & 8 \\
\hline Li [19] & 2004 & China & 270 & $P>1 \%$ & MMP2, MMP9 & $\checkmark$ & & & $\checkmark$ & $\checkmark$ & & $\checkmark$ & & 6 \\
\hline Rahko [23] & 2004 & Finland & 168 & $P>1 \%$ & MMP9 & $\checkmark$ & & & $\checkmark$ & $\checkmark$ & & $\checkmark$ & $\checkmark$ & 7 \\
\hline Ban [52] & 2004 & China & 60 & $\mathrm{SI} \geq 3$ & MMP2 & & $\checkmark$ & & & & & $\checkmark$ & & 7 \\
\hline Sivula & 2005 & Finland & 194 & $P>20 \%$ & MMP2 & $\checkmark$ & $\checkmark$ & & $\checkmark$ & $\checkmark$ & & & & 7 \\
\hline Zhou [42] & 2005 & China & 112 & $P>5 \%$ & MMP2 & & $\checkmark$ & $\checkmark$ & $\checkmark$ & $\checkmark$ & & & $\checkmark$ & 7 \\
\hline Mylona & 2007 & Greece & 175 & $P>20 \%$ & MMP9 & $\checkmark$ & $\checkmark$ & & $\checkmark$ & $\checkmark$ & & $\checkmark$ & $\checkmark$ & 6 \\
\hline $\mathrm{HaO}$ & 2007 & China & 76 & $\mathrm{SI} \geq 5$ & MMP9 & $\checkmark$ & $\checkmark$ & & $\checkmark$ & $\checkmark$ & & $\checkmark$ & $\checkmark$ & 7 \\
\hline Wu & 2008 & China & 60 & $P>50 \%$ & MMP9 & $\checkmark$ & $\checkmark$ & & $\checkmark$ & $\checkmark$ & & $\checkmark$ & $\checkmark$ & 7 \\
\hline Sullu [22] & 2011 & Turkey & 140 & $\mathrm{SI} \geq 5$ & MMP9 & $\checkmark$ & $\checkmark$ & $\checkmark$ & $\checkmark$ & $\checkmark$ & $\checkmark$ & & $\checkmark$ & 8 \\
\hline Zhao [18] & 2013 & China & 127 & $\mathrm{SI} \geq 6$ & MMP9 & $\checkmark$ & $\checkmark$ & & & & & $\checkmark$ & $\checkmark$ & 6 \\
\hline Zeng [36] & 2013 & China & 253 & $P>20 \%$ & MMP9 & $\checkmark$ & $\checkmark$ & & $\checkmark$ & $\checkmark$ & $\checkmark$ & $\checkmark$ & & 8 \\
\hline Wu & 2014 & China & 41 & $\mathrm{SI} \geq 1$ & MMP9 & & $\checkmark$ & & $\checkmark$ & $\checkmark$ & $\checkmark$ & $\checkmark$ & $\checkmark$ & 7 \\
\hline Tang & 2014 & China & 156 & $\mathrm{SI} \geq 6$ & MMP9 & $\checkmark$ & $\checkmark$ & & $\checkmark$ & $\checkmark$ & $\checkmark$ & $\checkmark$ & $\checkmark$ & 8 \\
\hline Min [32] & 2014 & Korea & 177 & $\mathrm{SI} \geq 1, \mathrm{SI} \geq 5$ & MMP2, MMP9 & $\checkmark$ & $\checkmark$ & & $\checkmark$ & $\checkmark$ & $\checkmark$ & $\checkmark$ & $\checkmark$ & 7 \\
\hline Youssef & 2014 & Egypt & 67 & $P>10 \%$ & MMP9 & $\checkmark$ & $\checkmark$ & & $\checkmark$ & $\checkmark$ & $\checkmark$ & $\checkmark$ & $\checkmark$ & 7 \\
\hline Huang [55] & 2014 & China & 147 & $P>10 \%$ & MMP9 & $\checkmark$ & & & & & & $\checkmark$ & & 6 \\
\hline Ramos [29] & 2016 & Brazil & 44 & $P>10 \%$ & MMP2 & $\checkmark$ & $\checkmark$ & $\checkmark$ & $\checkmark$ & $\checkmark$ & $\checkmark$ & $\checkmark$ & & 7 \\
\hline Li [16] & 2017 & China & 80 & $P>25 \%$ & MMP2, MMP9 & $\checkmark$ & $\checkmark$ & & & & & $\checkmark$ & & 7 \\
\hline Yang [28] & 2018 & Korea & 173 & $\mathrm{SI} \geq 2$ & MMP9 & $\checkmark$ & $\checkmark$ & & $\checkmark$ & $\checkmark$ & $\checkmark$ & $\checkmark$ & $\checkmark$ & 8 \\
\hline Zhang [56] & 2019 & China & 127 & $\mathrm{SI} \geq 6$ & MMP9 & $\checkmark$ & $\checkmark$ & & & & & $\checkmark$ & $\checkmark$ & 7 \\
\hline Zhou [54] & 2009 & China & 43 & $\mathrm{SI} \geq 3$ & MMP9 & $\checkmark$ & $\checkmark$ & & & & & $\checkmark$ & $\checkmark$ & 7 \\
\hline Joseph [27] & 2020 & British & 675 & $\mathrm{SI}$ & MMP9 & $\checkmark$ & $\checkmark$ & & $\checkmark$ & $\checkmark$ & & $\checkmark$ & $\checkmark$ & 8 \\
\hline
\end{tabular}

${ }^{a}$ Cut-off for overexpression of matrix metalloproteinases in tumor cells by immunohistochemistry

$P$ percentage of stained cells, $S /$ staining index considering both percentage and intensity of staining, $T$ tumor size, $N$ lymph node status, $M$ distant metastasis, $E R$ estrogen receptor, $P R$ progesterone receptor, HER2 human epidermal growth factor receptor 2, S TNM stage, G histological grade

for IHC staining (Table 3, Table S2). Subgroup of multivariate analysis adjusting $\mathrm{HR}$ for the other confounders (ER, PR, HER2, clinicopathological features) revealed that MMP2 overexpression was associated with unfavorable OS (HR $=1.78,95 \% \mathrm{CI} 1.32-2.39, P<0.001)$ and may be an independent prognostic factor.

\section{MMP9 overexpression and survival}

We found an association between MMP9 overexpression and DFS that almost reached significance $(\mathrm{HR}=1.73$, 95\%CI $0.99-3.01, P=0.052$ ), whereas subgroup of univariate and multivariate analysis both suggested a shorter DFS $(P=0.034$ and 0.006 , respectively). MMP9 overexpression was not associated with RFS (HR $=1.53$, $95 \%$ CI $0.73-3.18, P=0.259, \mathrm{I}^{2}=79.7 \%$ ) when we used a random-effect model. For OS, we pooled 18 studies with 2687 patients together by a fixed-effect model. The pooled HR was 1.52 (95\% CI 1.30-1.77, $P<0.001$, Fig. 3), suggesting an unfavorable OS in patients with overexpressed MMP9. A significantly shorter OS with MMP9 overexpression was found in Asian patients $(\mathrm{HR}=1.58$, 95\% CI 1.34-1.86, $P<0.001$ ) but not in Caucasian patients $(P=0.344)$ which may be due to small sample size $(n=744)$. The association was also significant in all of 
Table 3 Association between MMP2 overexpression and survival in patients with breast cancer

\begin{tabular}{|c|c|c|c|c|c|c|c|}
\hline Survival & Subgroup & No. of studies & No. of patients & $I^{2}(\%)$ & P for heterogeneity & Pooled HR $(95 \% \mathrm{Cl})$ & P for effect size \\
\hline DFS & Overall & 3 & 240 & 0 & 0.724 & $1.79(0.90-3.54)$ & 0.096 \\
\hline \multirow[t]{18}{*}{ OS } & Overall & 14 & 2128 & 30.6 & 0.131 & $1.60(1.33-1.94)$ & $<0.001$ \\
\hline & Ethnicity & & & & & & \\
\hline & Caucasians & 7 & 1100 & 0 & 0.569 & $2.21(1.47-3.06)$ & $<0.001$ \\
\hline & Asians & 7 & 1028 & 47.5 & 0.075 & $1.75(1.14-2.70)$ & 0.011 \\
\hline & IHC analysis standard & & & & & & \\
\hline & Percentage & 7 & 1228 & 0 & 0.729 & $1.97(1.46-2.68)$ & $<0.001$ \\
\hline & $\mathrm{SI}$ & 7 & 900 & 53.2 & 0.046 & $1.87(1.08-3.26)$ & 0.026 \\
\hline & HR data & & & & & & \\
\hline & Reported & 9 & 1706 & 51.5 & 0.036 & $1.95(1.37-2.79)$ & $<0.001$ \\
\hline & Estimated & 5 & 422 & 0 & 0.641 & $1.90(0.89-4.07)$ & 0.097 \\
\hline & Analysis model & & & & & & \\
\hline & Univariate & 9 & 1245 & 32.2 & 0.160 & $1.52(1.19-1.94)$ & 0.001 \\
\hline & Multivariate & 6 & 1153 & 29.9 & 0.211 & $1.78(1.33-2.39)$ & $<0.001$ \\
\hline & Sample size & & & & & & \\
\hline & $>150$ & 5 & 796 & 23.3 & 0.266 & $1.43(1.15-1.78)$ & 0.002 \\
\hline & $\leq 150$ & 9 & 1332 & 20.2 & 0.263 & $2.19(1.53-3.13)$ & $<0.001$ \\
\hline & Cancer subtype & & & & & & \\
\hline & IDC & 4 & 621 & 48.0 & 0.123 & $1.35(1.06-1.73)$ & 0.017 \\
\hline RFS & Overall & 5 & 712 & 0 & 0.892 & $1.21(0.82-1.81)$ & 0.338 \\
\hline
\end{tabular}

OS overall survival, DFS disease-free survival, RFS recurrence-free survival, IHC immunohistochemistry, IDC infiltrating ductal carcinoma, $S /$ staining index, $H R$ hazard ratio

the other subgroup analyses regarding IHC analysis standard, analysis model, HR data source, sample size, tissue and antibody used for IHC analysis (Table 4, Table S2). In addition, MMP9 overexpression was correlated with unfavorable $\mathrm{OS}$ in patients with IDC (HR = 1.37, 95\% CI 1.11-1.68, $P=0.003)$ and triple-negative breast cancer $(\mathrm{TNBC})(\mathrm{HR}=1.88,95 \% \mathrm{CI} 1.39-2.55, P<$ $0.001)$.

\section{MMPs overexpression and clinicopathological features}

We investigated the associations between MMP2/MMP9 overexpression and clinicopathological features (Table 5, Table S3, Table S4). MMP2 overexpression was significantly associated with higher histological grades (for grade $2-3$ vs $1, \mathrm{OR}=2.11, P<0.001$; for grade 3 vs. $1-2$, $\mathrm{OR}=1.53, P=0.005$; Fig. 4), higher tumor stages $(\mathrm{OR}=$ 2.09, $P=0.001)$ and distant metastasis $(\mathrm{OR}=2.69, P=$ $0.005)$, but not with the other clinicopathological features. Meanwhile, MMP9 overexpression was found to be associated with higher histological grades (grade 3 vs. $1-2$, OR $=1.77, P<0.001$ ), larger tumor size (for $>2 \mathrm{~cm}$ vs. $\leq 2 \mathrm{~cm}, \mathrm{OR}=1.32,95 \%$ CI 1.13-1.54, $P<0.001$; for $>$ $5 \mathrm{~cm}$ vs. $\leq 5 \mathrm{~cm}, \mathrm{OR}=2.02$, 95\%CI $1.28-3.17, P=0.002$; Fig. 5), lymph node metastasis $(\mathrm{OR}=2.90, P<0.001)$, and positive HER2 $(\mathrm{OR}=1.41, P=0.021)$.

\section{Sensitivity analysis and meta-regression}

Sensitivity analysis revealed that excluding a single study did not obviously change the pooled effect size. Metaregression showed that sample size had a significant impact on the association of PR status with MMP9 overexpression $(P=0.025)$ and ER status with MMP2 overexpression $(P=0.004)$.

\section{Publication bias}

We observed significant publication bias in the analysis of the association of MMP2 overexpression with survival $(P<0.05)$, ER status $(P=0.003)$, and lymph node metastasis $(P=0.003)$, as well as MMP9 overexpression with lymph node status $(P=0.045)$ and TNM stage $(P=$ 0.042 ). In the other analyses, the funnel plots were symmetric and $P$ values of Egger's test were $>0.05$, indicating there was no obvious publication bias.

\section{Discussion}

MMP2 and MMP9, also known as Gelatinase A and B, play key roles in the carcinogenesis of $\mathrm{BC}$, with functions in cell proliferation, inflammation, angiogenesis, tumor invasion and metastasis [60]. However, studies on the potential associations between MMP2/9 expression and clinicopathological features and survival in $\mathrm{BC}$ have yielded conflicting results. Here, we performed a meta- 


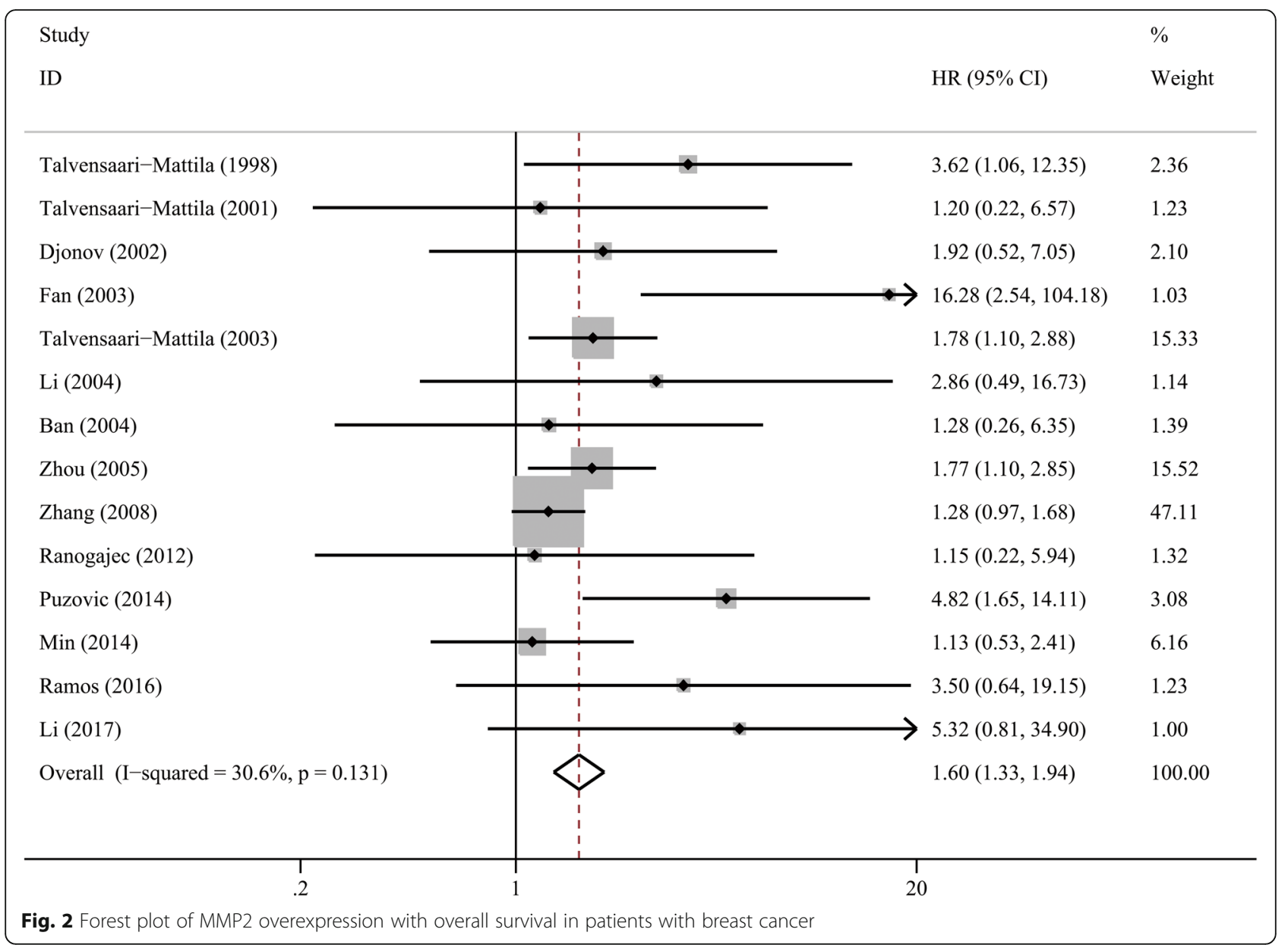

analysis including 41 studies with $6517 \mathrm{BC}$ patients and evaluated the prognostic values of $\mathrm{MMP} 2 / 9$ expression in tumor cells for BC. We found that MMP2 overexpression was significantly associated with shorter OS while MMP9 overexpression was related to shorter DFS and OS, indicating that MMP2 and MMP9 may serve as promising prognostic biomarkers for the treatment and management of $\mathrm{BC}$ patients.

Tumor metastasis is a crucial event of BC that severely affects the survival of patients, and may influence the determination of appropriate therapeutic strategies [61]. Overproduction of MMP2//9 induces the degradation of the major components of ECM and BM, allowing the escape of tumor cells and promoting subsequent metastasis [62]. Higher expression of MMP2/9 was found in tumor tissues compared with adjacent normal tissues [16]. In present study, MMP2 overexpression was associated with higher risk of distant metastasis and MMP9 overexpression correlated with lymph node metastasis, suggesting MMP2/9 may be indicators for BC metastasis. Moreover, both markers were associated with advanced clinical stages and poor tumor differentiation of BC. Therefore, MMP2/9 may be markers for poor prognosis and the detection of MMP2/9 protein expression may help determine strategies for treatment and follow-ups.

As described above, MMP2/9 overexpression has been associated with tumor size, metastasis, clinical stages and histological grades, all of which were well-known clinicopathological features influencing the survivals of $\mathrm{BC}$ patients. Therefore, the hazards ratio may be biased in univariate analysis and should be adjusted for these confounders using multivariate methods to investigate the independent roles of MMP2/9. In present analysis, subgroup of multivariate analysis demonstrated that both MMP2 and MMP9 overexpression predicted a significantly shorter OS after adjustment for known prognostic markers including ER, PR, HER2, and other clinicopathological features, indicating that MMP2 and MMP9 were independent predictors for survival of $\mathrm{BC}$ patients. Thus, MMP2/MMP9 overexpression with independent prognostic values may help make strategies for treatment and management of $\mathrm{BC}$ alone or together with known markers.

While the predictive roles of MMP2 and MMP9 were separately investigated in our meta-analysis, the role of 


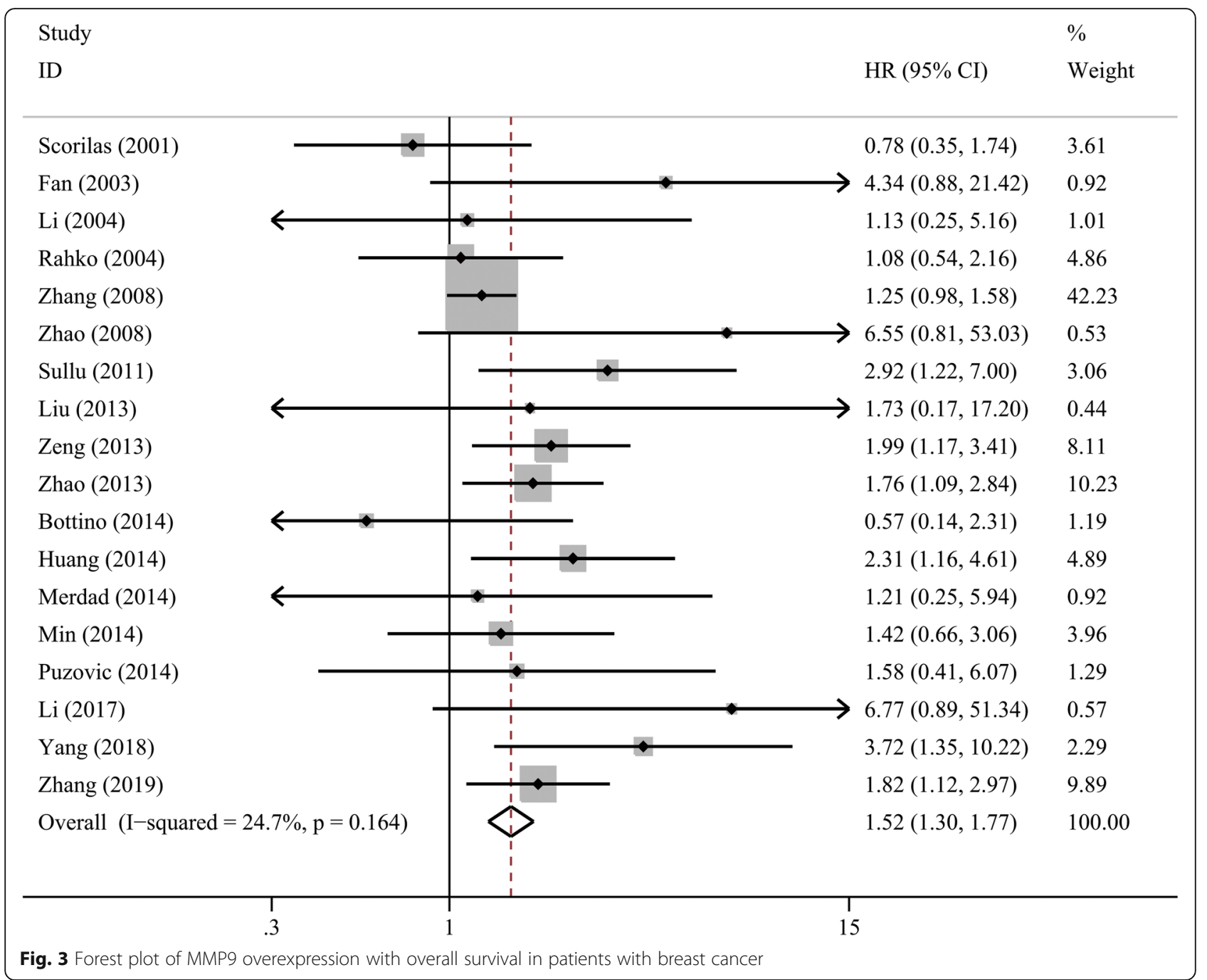

MMP2 and MMP9 co-expression were not studied because of the small number of eligible studies. Li et al [19] reported that MMP2/9 co-expression was associated with shorter RFS in univariate and multivariate analyses but not with OS. Whereas, Puzovic et al [35] did not find associations of MMP2/9 co-expression with DFS and OS in BC patients. Since MMP2 and MMP9 belong to the same subtype of matrix metalloproteinases and share similar mechanism in promoting carcinogenesis, it is necessary to explore the prognostic value of the co-expression of both proteins in $\mathrm{BC}$ patients.

The present study mainly focused on the protein expression in tumor cells and has excluded MMP2/9 mRNA and protein expression in serum and stromal cells. Several studies detected serum MMP2/9 expressions by ELISA and correlated them with survival outcomes in BC patients [63-66]. However, the optimal cutoffs for high- and low-expression were mostly established using the median values, which varied among studies and were largely dependent on the enrolled samples. Thus, it was not suitable to pool these studies together or with the studies investigating protein expression derived from tumor cells. More efforts are needed to establish the optimal cutoff for serum expression of MMP2/9.

Some studies detected MMP2/9 expression in stromal cells by semi-quantitative analysis with $\operatorname{IHC}[21,32,41]$. MMP2/9 are mainly expressed by neoplastic cells but also are derived from non-neoplastic stromal and inflammatory cells $[67,68]$. Stromal MMP2/9 may also participate in tumor tissue remodeling and contribute to cancer progression $[69,70]$. Min et al [32] found that stromal but not tumoral MMP2 was an independent predictive factor of OS, implying different prognostic roles of tumor- and stroma-derived MMP2 in BC. Mylona et al [41] reported significant associations of stromal MMP9 with poor OS and DFS. However, the prognostic value of stromal MMP2/9 in BC requires further investigation. Because the percentages of MMP2/9 
Table 4 Association between MMP9 overexpression and survival in patients with breast cancer

\begin{tabular}{|c|c|c|c|c|c|c|c|}
\hline Survival & Subgroup & No. of studies & No. of patients & $I^{2}(\%)$ & P for heterogeneity & Pooled HR $(95 \% \mathrm{Cl})$ & P for effect size \\
\hline \multirow[t]{4}{*}{ DFS } & Overall & 6 & 1002 & 70.5 & 0.005 & $1.73(0.99-3.01)$ & 0.052 \\
\hline & Analysis model & & & & & & \\
\hline & Univariate & 6 & 1002 & 74.4 & 0.002 & $1.86(1.05-3.31)$ & 0.034 \\
\hline & Multivariate & 3 & 573 & 56.7 & 0.100 & $2.73(1.33-5.61)$ & 0.006 \\
\hline \multirow[t]{20}{*}{ OS } & Overall & 18 & 2687 & 24.7 & 0.164 & $1.52(1.30-1.77)$ & $<0.001$ \\
\hline & Ethnicity & & & & & & \\
\hline & Caucasians & 6 & 744 & 22.0 & 0.268 & $1.21(0.81-1.80)$ & 0.344 \\
\hline & Asians & 12 & 1943 & 25.0 & 0.198 & $1.58(1.34-1.86)$ & $<0.001$ \\
\hline & $\mathrm{IHC}$ analysis stan & & & & & & \\
\hline & Percentage & 7 & 1178 & 2.8 & 0.404 & $1.85(1.32-2.59)$ & $<0.001$ \\
\hline & $\mathrm{SI}$ & 9 & 1239 & 24.4 & 0.226 & $1.51(1.26-1.80)$ & $<0.001$ \\
\hline & Other cut-offs & 2 & 270 & 0 & 0.703 & $0.72(0.36-1.45)$ & 0.359 \\
\hline & HR data & & & & & & \\
\hline & Reported & 14 & 2249 & 9.9 & 0.344 & $1.43(1.21-1.67)$ & $<0.001$ \\
\hline & Estimated & 4 & 438 & 0 & 0.644 & $2.84(1.71-4.73)$ & $<0.001$ \\
\hline & Analysis model & & & & & & \\
\hline & Univariate & 14 & 2190 & 63.8 & 0.001 & $1.79(1.24-2.59)$ & 0.002 \\
\hline & Multivariate & 9 & 1592 & 1.4 & 0.422 & $1.75(1.37-2.22)$ & $<0.001$ \\
\hline & Sample size & & & & & & \\
\hline & $>150$ & 8 & 1703 & 18.8 & 0.281 & $1.33(1.10-1.61)$ & 0.003 \\
\hline & $\leq 150$ & 10 & 984 & 0 & 0.494 & $1.97(1.51-2.56)$ & $<0.001$ \\
\hline & Cancer subtype & & & & & & \\
\hline & IDC & 6 & 934 & 43.3 & 0.116 & $1.37(1.11-1.68)$ & 0.003 \\
\hline & TNBC & 4 & 590 & 0 & 0.933 & $1.88(1.39-2.55)$ & $<0.001$ \\
\hline RFS & Overall & 5 & 1292 & 79.7 & 0.001 & $1.53(0.73-3.18)$ & 0.259 \\
\hline
\end{tabular}

OS overall survival, DFS disease-free survival, RFS recurrence-free survival, IHC immunohistochemistry, IDC infiltrating ductal carcinoma, TNBC triple-negative breast cancer, $S /$ staining index, HR hazard ratio

Table 5 Association between MMP2/9 overexpression and clinicopathological features in breast cancer patients

\begin{tabular}{|c|c|c|c|c|c|c|c|c|c|c|}
\hline \multirow{2}{*}{$\begin{array}{l}\text { Clinicopathological } \\
\text { feature }\end{array}$} & \multicolumn{5}{|l|}{ MMP2 } & \multicolumn{5}{|l|}{ MMP9 } \\
\hline & $\begin{array}{l}\text { No. of } \\
\text { patients }\end{array}$ & $I^{2}(\%)$ & Model & $\begin{array}{l}\text { Pooled OR } \\
(95 \% \mathrm{Cl})\end{array}$ & $P$ & $\begin{array}{l}\text { No. of } \\
\text { patients }\end{array}$ & $I^{2}(\%)$ & Model & $\begin{array}{l}\text { Pooled OR } \\
(95 \% \mathrm{Cl})\end{array}$ & $P$ \\
\hline Tumor size (> $2 \mathrm{~cm}$ vs $\leq 2 \mathrm{~cm}$ ) & 1254 & 48.4 & $\mathrm{R}$ & $1.17(0.78-1.75)$ & 0.448 & 3005 & 0 & $\mathrm{~F}$ & $1.32(1.13-1.54)$ & $<0.001$ \\
\hline Tumor size (> $5 \mathrm{~cm}$ vs $\leq 5 \mathrm{~cm}$ ) & 1286 & 15.9 & $\mathrm{~F}$ & $1.12(0.76-1.64)$ & 0.568 & 924 & 0 & $\mathrm{~F}$ & $2.02(1.28-3.17)$ & 0.002 \\
\hline Lymph node status (+ vs -) & 1606 & 40.3 & $\mathrm{R}$ & $1.22(0.88-1.70)$ & 0.225 & 1945 & 77.1 & $\mathrm{R}$ & $2.90(1.86-4.53)$ & $<0.001$ \\
\hline Distant metastasis (+ vs -) & 219 & 22.0 & $\mathrm{~F}$ & $2.69(1.35-5.39)$ & 0.005 & - & - & - & - & - \\
\hline ER (+ vs -) & 1784 & 47.1 & $\mathrm{R}$ & $0.82(0.57-1.18)$ & 0.290 & 1975 & 58.2 & $\mathrm{R}$ & $1.00(0.71-1.39)$ & 0.990 \\
\hline PR (+ vs -) & 1660 & 5.7 & $\mathrm{~F}$ & $1.07(0.85-1.35)$ & 0.545 & 1876 & 55.2 & $\mathrm{R}$ & $1.00(0.73-1.38)$ & 0.991 \\
\hline HER2 (+ vs -) & 361 & 64.8 & $\mathrm{R}$ & $1.28(0.49-3.37)$ & 0.612 & 1007 & 0 & $\mathrm{~F}$ & $1.41(1.05-1.90)$ & 0.021 \\
\hline TNM stage (III-IV vs I-II) & 666 & 28.0 & $\mathrm{~F}$ & $2.09(1.36-3.21)$ & 0.001 & 2419 & 70.7 & $\mathrm{R}$ & $2.00(1.26-3.19)$ & 0.004 \\
\hline Grade (2-3 vs 1) & 1437 & 0 & $\mathrm{~F}$ & $2.11(1.55-2.88)$ & $<0.001$ & 2051 & 61.9 & $\mathrm{R}$ & $1.55(0.91-2.62)$ & 0.107 \\
\hline Grade (3 vs 1-2) & 1089 & 0 & $\mathrm{~F}$ & $1.53(1.14-2.06)$ & 0.005 & 2609 & 48.4 & $\mathrm{R}$ & $1.77(1.32-2.36)$ & $<0.001$ \\
\hline
\end{tabular}




\begin{tabular}{lllll|}
\hline Study & & & \multicolumn{2}{l|}{ OR (95\% CI) } \\
Weight \\
ID
\end{tabular}

overexpression were much higher in tumor cells compared with in stromal cells under the same IHC criteria [32, 41], we focused on tumoral MMP2/9 and excluded stromal MMP2/9 to keep the homogeneity of eligible studies in present study.

IDC is the most common subtype of BC [71]. Subgroup analysis demonstrated that MMP2/9 overexpression predicted significantly shorter OS in patients with IDC. TNBC is featured by the lack of ER, PR, and HER2 expression and comprises almost one-fifth of $\mathrm{BC}$ cases [72] and new prognostic indicators and treatment approaches for TNBC are urgently needed. Our analysis demonstrated that MMP9 overexpression was associated with poorer OS, larger tumor size, and higher TNM stage in TNBC, suggesting the promising role of MMP9 in the prognosis of TNBC.

There are some limitations in our study. Firstly, the HR and corresponding 95\% CI in some studies were estimated from survival curves, which may deviate from the true values and affect the pooled effect sizes. For example, a significant association between MMP2 and OS was found in the subgroup with reported data but not in the subgroup with estimated data. To minimize the inaccuracy, two researchers independently extracted the data from survival curves. Secondly, there is currently no consensus on the threshold for MMPs overexpression by IHC. The cut-off values for percentage or staining index differ between studies, resulting in inconsistent positivity rates and predictive values of MMPs overexpression. This may be an important source of heterogeneity and limit the clinical use of MMP expression for the prediction of BC prognosis. Thirdly, we found obvious publication bias in the analysis of MMP overexpression associated with survival. The bias may potentially come from studies with univariate analysis (Egger's test, $P<$ 


\begin{tabular}{|c|c|c|}
\hline $\begin{array}{l}\text { Study } \\
\text { ID }\end{array}$ & OR $(95 \% \mathrm{CI})$ & $\begin{array}{l}\% \\
\text { Weight }\end{array}$ \\
\hline \multicolumn{3}{|l|}{ Tumor size (cutoff: $2 \mathrm{~cm}$ ) } \\
\hline Scorilas (2001) & $1.02(0.53,1.94)$ & 6.70 \\
\hline $\operatorname{Li}(2004)$ & $1.23(0.74,2.04)$ & 9.75 \\
\hline Rahko (2004) & $1.16(0.62,2.17)$ & 6.58 \\
\hline Hao (2007) & $0.93(0.35,2.44)$ & 3.11 \\
\hline Mylona (2007) & $1.71(0.81,3.60)$ & 3.67 \\
\hline Wu (2008) & $0.21(0.01,4.06)$ & 1.11 \\
\hline Sullu (2011) & $1.59(0.77,3.27)$ & 4.23 \\
\hline Zeng (2013) & $1.17(0.71,1.94)$ & 10.17 \\
\hline Zhao (2013) & $2.67(1.30,5.49)$ & 3.31 \\
\hline Huang (2014) & $1.46(0.76,2.81)$ & 5.43 \\
\hline $\operatorname{Min}(2014)$ & $1.09(0.59,2.02)$ & 7.05 \\
\hline Tang (2014) & $1.12(0.57,2.22)$ & 5.69 \\
\hline $\mathrm{Wu}(2014)$ & $1.92(0.33,10.98)$ & 0.64 \\
\hline Yang (2018) & $1.11(0.59,2.07)$ & 6.86 \\
\hline Zhang (2019) & $2.67(1.30,5.49)$ & 3.31 \\
\hline Zhou (2019) & $1.35(0.20,9.02)$ & 0.68 \\
\hline Joseph (2020) & $1.29(0.92,1.81)$ & 21.70 \\
\hline Subtotal $(\mathrm{I}-$ squared $=0.0 \%, \mathrm{p}=0.718)$ & $1.32(1.13,1.54)$ & 100.00 \\
\hline \multicolumn{3}{|l|}{ Tumor size (cutoff: $5 \mathrm{~cm}$ ) } \\
\hline Fan (2003) & $4.75(0.98,23.14)$ & 6.28 \\
\hline & \multicolumn{2}{|l|}{$4.17(1.19,14.60)$} \\
\hline \multicolumn{3}{|c|}{$1.71(0.44,6.71)$} \\
\hline \multicolumn{3}{|c|}{$0.95(0.37,2.43)$} \\
\hline \multicolumn{3}{|c|}{$3.07(0.16,60.57)$} \\
\hline \multicolumn{3}{|c|}{$1.40(0.06,30.48)$} \\
\hline \multicolumn{3}{|c|}{$2.67(0.96,7.39)$} \\
\hline \multicolumn{3}{|c|}{$1.21(0.40,3.68)$} \\
\hline Subtotal $(\mathrm{I}-$ squared $=0.0 \%, \mathrm{p}=0.518)$ & $2.02(1.28,3.17)$ & 100.00 \\
\hline \multicolumn{3}{|l|}{. } \\
\hline$T$ & T & \\
\hline .1 & 15 & \\
\hline
\end{tabular}

0.05 ) but not multivariate analysis (Egger's test, $P>0.05$ ), since studies with negative results of univariate analysis may tend to be unpublished.

\section{Conclusions}

Our meta-analysis demonstrated that MMP2 and MMP9 overexpression in tumor cells was associated with poor survival, larger tumor size, lymph node metastasis, distant metastasis, higher clinical stage, and histological grade in patients with $\mathrm{BC}$. These results suggest that
MMP2 and MMP9 are potential markers for the prediction of $\mathrm{BC}$ prognosis.

\section{Supplementary Information}

The online version contains supplementary material available at https://doi. org/10.1186/s12885-021-07860-2.

Additional file 1: Table S1. Tissues and antibodies for immunohistochemistry. Table S2. Subgroup analysis of overall survival stratified by immunohistochemistry antibody. Table S3. Subgroup analysis of association between MMP2 overexpression and

clinicopathological features in breast cancer patients. Table S4. 
Subgroup analysis of association between MMP9 overexpression and clinicopathological features in breast cancer patients.

\section{Abbreviations}

MMP: Matrix metalloproteinases; OS: Overall survival; DFS: Disease-free survival; RFS: Recurrence-free survival; HR: Hazard ratio; OR: Odds ratio; BC: Breast cancer; IDC: Infiltrating ductal cancer; TNBC: Triple-negative breast cancer; IHC: Immunohistochemistry

\section{Acknowledgements}

Not applicable.

\section{Authors' contributions}

$\mathrm{HJ}$ and $\mathrm{HL}$ conceived and designed the study, collected, analyzed and interpreted the data. $\mathrm{HJ}$ drafted the manuscript. $\mathrm{HJ}$ and $\mathrm{HL}$ critically revised the manuscript and approved the submission.

\section{Funding}

Not applicable.

\section{Availability of data and materials}

The datasets used and/or analyzed during the current study are available from the corresponding author on reasonable request.

\section{Ethics approval and consent to participate}

Not applicable.

\section{Consent for publication}

Not applicable.

\section{Competing interests}

The authors declare that they have no competing interests.

\section{Received: 6 September 2020 Accepted: 31 January 2021} Published online: 10 February 2021

\section{References}

1. Bray F, Ferlay J, Soerjomataram I, Siegel RL, Torre LA, Jemal A. Global cancer statistics 2018: GLOBOCAN estimates of incidence and mortality worldwide for 36 cancers in 185 countries. CA Cancer J Clin. 2018;68(6):394-424.

2. Ferlay J, Soerjomataram I, Dikshit R, Eser S, Mathers C, Rebelo M, Parkin DM, Forman D, Bray F. Cancer incidence and mortality worldwide: sources, methods and major patterns in GLOBOCAN 2012. Int J Cancer. 2015;136(5): E359-86.

3. Parise CA, Bauer KR, Brown MM, Caggiano V. Breast cancer subtypes as defined by the estrogen receptor (ER), progesterone receptor (PR), and the human epidermal growth factor receptor 2 (HER2) among women with invasive breast cancer in California, 1999-2004. Breast J. 2009;15(6):593-602.

4. Marti JLG, Hyder T, Nasrazadani A, Brufsky AM. The evolving landscape of HER2-directed breast Cancer therapy. Curr Treat Options in Oncol. 2020; 21(10):82.

5. Nagase $H$, Visse $R$, Murphy $G$. Structure and function of matrix metalloproteinases and TIMPs. Cardiovasc Res. 2006;69(3):562-73.

6. Raeeszadeh-Sarmazdeh M, Do LD, Hritz BG. Metalloproteinases and Their Inhibitors: Potential for the Development of New Therapeutics. Cells. 2020; 9(5):1313.

7. Vandooren J, Van den Steen PE, Opdenakker G. Biochemistry and molecular biology of gelatinase B or matrix metalloproteinase-9 (MMP-9): the next decade. Crit Rev Biochem Mol Biol. 2013;48(3):222-72.

8. Nelson AR, Fingleton B, Rothenberg ML, Matrisian LM. Matrix metalloproteinases: biologic activity and clinical implications. J Clin Oncol. 2000;18(5):1135-49.

9. Gialeli $C$, Theocharis $A D$, Karamanos NK. Roles of matrix metalloproteinases in cancer progression and their pharmacological targeting. FEBS J. 2011; 278(1):16-27.

10. Hojilla CV, Mohammed FF, Khokha R. Matrix metalloproteinases and their tissue inhibitors direct cell fate during cancer development. Br J Cancer. 2003;89(10):1817-21.

11. Klein T, Bischoff R. Physiology and pathophysiology of matrix metalloproteases. Amino Acids. 2011;41(2):271-90.
12. Deng W, Peng W, Wang T, Chen J, Zhu S. Overexpression of MMPs functions as a prognostic biomarker for Oral Cancer patients: a systematic review and meta-analysis. Oral Health Prev Dent. 2019;17(6):505-14.

13. Zhu J, Zhang X, Ai L, Yuan R, Ye J. Clinicohistopathological implications of MMPNEGF expression in retinoblastoma: a combined meta-analysis and bioinformatics analysis. J Transl Med. 2019;17(1):226.

14. Miao C, Liang C, Zhu J, Xu A, Zhao K, Hua Y, Zhang J, Chen W, Suo C, Zhang $C$, et al. Prognostic role of matrix metalloproteinases in bladder carcinoma: a systematic review and meta-analysis. Oncotarget. 2017;8(19): 32309-21.

15. Jia H, Zhang Q, Liu F, Zhou D. Prognostic value of MMP-2 for patients with ovarian epithelial carcinoma: a systematic review and meta-analysis. Arch Gynecol Obstet. 2017;295(3):689-96.

16. Li H, Qiu Z, Li F, Wang C. The relationship between MMP-2 and MMP-9 expression levels with breast cancer incidence and prognosis. Oncol Lett. 2017;14(5):5865-70.

17. Liu Y, Xin T, Jiang QY, Huang DY, Shen WX, Li L, LV YJ, Jin YH, Song XW, Teng C. CD147, MMP9 expression and clinical significance of basal-like breast cancer. Med Oncol. 2013;30(1):366.

18. Zhao S, Ma W, Zhang M, Tang D, Shi Q, Xu S, Zhang X, Liu Y, Song Y, Liu L, et al. High expression of CD147 and MMP-9 is correlated with poor prognosis of triple-negative breast cancer (TNBC) patients. Med Oncol. 2013; 30(1):335.

19. Li HC, Cao DC, Liu Y, Hou YF, Wu J, Lu JS, Di GH, Liu G, Li FM, Ou ZL, et al. Prognostic value of matrix metalloproteinases (MMP-2 and MMP-9) in patients with lymph node-negative breast carcinoma. Breast Cancer Res Treat. 2004;88(1):75-85.

20. Merdad A, Karim S, Schulten HJ, Dallol A, Buhmeida A, Al-Thubaity F, Gari MA, Chaudhary AG, Abuzenadah AM, Al-Qahtani MH. Expression of matrix metalloproteinases (MMPs) in primary human breast cancer: MMP-9 as a potential biomarker for cancer invasion and metastasis. Anticancer Res. 2014;34(3):1355-66.

21. Fernandez-Guinea O, Alvarez-Cofino A, Eiro N, Gonzalez LO, del Casar JM, Fernandez-Garcia B, Lamelas ML, Andicoechea A, Vizoso FJ. Low microvascular density at the tumor center is related to the expression of metalloproteases and their inhibitors and with the occurrence of distant metastasis in breast carcinomas. Int J Clin Oncol. 2013;18(4):629-40.

22. Sullu Y, Demirag GG, Yildirim A, Karagoz F, Kandemir B. Matrix metalloproteinase-2 (MMP-2) and MMP-9 expression in invasive ductal carcinoma of the breast. Pathol Res Pract. 2011;207(12):747-53.

23. Rahko E, Jukkola A, Melkko J, Paavo P, Bloigu R, Talvensaari-Mattila A, Turpeenniemi-Hujanen T. Matrix metalloproteinase-9 (MMP-9) immunoreactive protein has modest prognostic value in locally advanced breast carcinoma patients treated with an adjuvant antiestrogen therapy. Anticancer Res. 2004;24(6):4247-53.

24. Moher D, Liberati A, Tetzlaff J, Altman DG, Group P. Preferred reporting items for systematic reviews and meta-analyses: the PRISMA statement. J Clin Epidemiol. 2009;62(10):1006-12.

25. Stang A. Critical evaluation of the Newcastle-Ottawa scale for the assessment of the quality of nonrandomized studies in meta-analyses. Eur J Epidemiol. 2010;25(9):603-5.

26. Tierney JF, Stewart LA, Ghersi D, Burdett S, Sydes MR. Practical methods for incorporating summary time-to-event data into meta-analysis. Trials. 2007;8: 16.

27. Joseph C, Alsaleem M, Orah N, Narasimha PL, Miligy IM, Kurozumi S, Ellis IO, Mongan NP, Green AR, Rakha EA. Elevated MMP9 expression in breast cancer is a predictor of shorter patient survival. Breast Cancer Res Treat. 2020;182(2):267-82.

28. Yang J, Min KW, Kim DH, Son BK, Moon KM, Wi YC, Bang SS, Oh YH, Do SI, Chae SW, et al. High TNFRSF12A level associated with MMP-9 overexpression is linked to poor prognosis in breast cancer: gene set enrichment analysis and validation in large-scale cohorts. PLoS One. 2018; 13(8):e0202113.

29. Ramos EA, Silva CT, Manica GC, Pereira IT, Klassen LM, Ribeiro EM, Cavalli IJ, Braun-Prado K, Lima RS, Urban CA, et al. Worse prognosis in breast cancer patients can be predicted by immunohistochemical analysis of positive MMP-2 and negative estrogen and progesterone receptors. Rev Assoc Med Bras (1992). 2016;62(8):774-81.

30. Yousef EM, Tahir MR, St-Pierre Y, Gaboury LA. MMP-9 expression varies according to molecular subtypes of breast cancer. BMC Cancer. 2014;14: 609. 
31. Youssef NS, Hakim SA. Association of Fascin and matrix metalloproteinase-9 expression with poor prognostic parameters in breast carcinoma of Egyptian women. Diagn Pathol. 2014;9:136.

32. Min KW, Kim DH, Do SI, Kim K, Lee HJ, Chae SW, Sohn JH, Pyo JS, Oh YH, Kim WS, et al. Expression patterns of stromal MMP-2 and tumoural MMP-2 and -9 are significant prognostic factors in invasive ductal carcinoma of the breast. APMIS. 2014;122(12):1196-206.

33. Tang D, Piao Y, Zhao S, Mu X, Li S, Ma W, Song Y, Wang J, Zhao W, Zhang $\mathrm{Q}$. Expression and correlation of matrix metalloproteinase- 9 and heparanase in patients with breast cancer. Med Oncol. 2014;31(7):26.

34. Wu QW, Yang QM, Huang YF, She HQ, Liang J, Yang QL, Zhang ZM. Expression and clinical significance of matrix metalloproteinase-9 in lymphatic invasiveness and metastasis of breast cancer. PLoS One. 2014;9(5):e97804.

35. Puzovic V, Brcic I, Ranogajec I, Jakic-Razumovic J. Prognostic values of ETS-1, MMP-2 and MMP-9 expression and co-expression in breast cancer patients. Neoplasma. 2014;61(4):439-46.

36. Zeng Y, Liu C, Dong B, Li Y, Jiang B, Xu Y, Meng L, Wu J, Qu L, Shou C. Inverse correlation between Naa10p and MMP-9 expression and the combined prognostic value in breast cancer patients. Med Oncol. 2013;30(2):562.

37. Ranogajec I, Jakic-Razumovic J, Puzovic V, Gabrilovac J. Prognostic value of matrix metalloproteinase-2 (MMP-2), matrix metalloproteinase-9 (MMP-9) and aminopeptidase N/CD13 in breast cancer patients. Med Oncol. 2012; 29(2):561-9.

38. Zhang B, Cao X, Liu Y, Cao W, Zhang F, Zhang S, Li H, Ning L, Fu L, Niu Y, et al. Tumor-derived matrix metalloproteinase-13 (MMP-13) correlates with poor prognoses of invasive breast cancer. BMC Cancer. 2008;8:83.

39. Wu ZS, Wu Q, Yang JH, Wang HQ, Ding XD, Yang F, Xu XC. Prognostic significance of MMP-9 and TIMP-1 serum and tissue expression in breast cancer. Int J Cancer. 2008;122(9):2050-6.

40. Hao L, Zhang C, Qiu Y, Wang L, Luo Y, Jin M, Zhang Y, Guo TB, Matsushima K, Zhang Y. Recombination of CXCR4, VEGF, and MMP-9 predicting lymph node metastasis in human breast cancer. Cancer Lett. 2007;253(1):34-42

41. Mylona E, Nomikos A, Magkou C, Kamberou M, Papassideri I, Keramopoulos A, Nakopoulou L. The clinicopathological and prognostic significance of membrane type 1 matrix metalloproteinase (MT1-MMP) and MMP-9 according to their localization in invasive breast carcinoma. Histopathology. 2007:50(3):338-47.

42. Zhou S, Liu C, Wu SM, Wu RL. Expressions of CD147 and matrix metalloproteinase-2 in breast cancer and their correlations to prognosis. $\mathrm{Ai}$ Zheng. 2005;24(7):874-9

43. Sivula A, Talvensaari-Mattila A, Lundin J, Joensuu H, Haglund C, Ristimaki A, Turpeenniemi-Hujanen T. Association of cyclooxygenase-2 and matrix metalloproteinase-2 expression in human breast cancer. Breast Cancer Res Treat. 2005;89(3):215-20.

44. Talvensaari-Mattila A, Paakko P, Turpeenniemi-Hujanen T. Matrix metalloproteinase-2 (MMP-2) is associated with survival in breast carcinoma. Br J Cancer. 2003;89(7):1270-5.

45. Fan SQ, Wei QY, Li MR, Zhang LQ, Liang QC. Expression and clinical significance of MMP-2, MMP-9,TIMP-1, and TIMP-2 in breast carcinoma. Ai Zheng. 2003;22(9):968-73.

46. Nakopoulou L, Tsirmpa I, Alexandrou P, Louvrou A, Ampela C, Markaki S, Davaris PS. MMP-2 protein in invasive breast cancer and the impact of MMP-2/TIMP-2 phenotype on overall survival. Breast Cancer Res Treat. 2003;77(2):145-55.

47. Hirvonen R, Talvensaari-Mattila A, Paakko P, Turpeenniemi-Hujanen T. Matrix metalloproteinase-2 (MMP-2) in T(1-2)NO breast carcinoma. Breast Cancer Res Treat. 2003;77(1):85-91.

48. Djonov V, Cresto N, Aebersold DM, Burri PH, Altermatt HJ, Hristic M, Berclaz G, Ziemiecki A, Andres AC. Tumor cell specific expression of MMP-2 correlates with tumor vascularisation in breast cancer. Int J Oncol. 2002;21(1):25-30.

49. Talvensaari-Mattila A, Paakko P, Blanco-Sequeiros G, Turpeenniemi-Hujanen T. Matrix metalloproteinase-2 (MMP-2) is associated with the risk for a relapse in postmenopausal patients with node-positive breast carcinoma treated with antiestrogen adjuvant therapy. Breast Cancer Res Treat. 2001;65(1):55-61.

50. Talvensaari-Mattila A, Paakko P, Turpeenniemi-Hujanen T. MMP-2 positivity and age less than 40 years increases the risk for recurrence in premenopausal patients with node-positive breast carcinoma. Breast Cancer Res Treat. 1999:58(3):287-93.

51. Talvensaari-Mattila A, Paakko P, Hoyhtya M, Blanco-Sequeiros G, TurpeenniemiHujanen T. Matrix metalloproteinase-2 immunoreactive protein: a marker of aggressiveness in breast carcinoma. Cancer. 1998;83(6):1153-62.
52. Ban SY, Tan XX, Qiao JJ. The relationship between MMP-2 and TIMP2 expression and metastasisi and prognosis of breat infiltrative ductal cancer. J Postgrad Med. 2004;27(6):27-9.

53. Zhao JX, Lin MZ, Yao HW, Wan YL. The expression of transferrin and MMP-9 in breast cancer and its significance in prognosis. Chin J Clin Oncol. 2008; 35(1):22-5.

54. Zhou N, Tan XS, Xu TT, Wang FR, Hu SY. Expression of RECK and MMP9 proteins in triple negative breast cancer and the relationship with clinical characteristics and prognosis. Oncol Progress. 2019;17(16):1942-5.

55. Huang S, Chen J, Jia YJ, Wang YK, Lu YS, Wu KJ. Research on the correlation of MMP9 and P53 expression with the prognosis of triple negative breast cancer. Progress Modern Biomed. 2014;14(5):881-4.

56. Zhang J, Yao SH, Wang XH. Expression of CD147 and matrix metalloproteinases 9 in triple-begative creast cancer before neoadjuvant chemotherapy and its guiding significance. Eval Anal Drug-Use Hospit China. 2019;19(11):1321-3.

57. Scorilas A, Karameris A, Arnogiannaki N, Ardavanis A, Bassilopoulos P, Trangas T, Talieri M. Overexpression of matrix-metalloproteinase-9 in human breast cancer: a potential favourable indicator in node-negative patients. $\mathrm{Br}$ J Cancer. 2001;84(11):1488-96.

58. Pellikainen JM, Ropponen KM, Kataja W, Kellokoski JK, Eskelinen MJ, Kosma VM. Expression of matrix metalloproteinase (MMP)-2 and MMP-9 in breast cancer with a special reference to activator protein-2, HER2, and prognosis. Clin Cancer Res. 2004;10(22):7621-8.

59. Bottino J, Gelaleti GB, Maschio LB, Jardim-Perassi BV, Zuccari DA. Immunoexpression of ROCK-1 and MMP-9 as prognostic markers in breast cancer. Acta Histochem. 2014;116(8):1367-73.

60. Dofara SG, Chang SL, Diorio C. Gene polymorphisms and circulating levels of MMP-2 and MMP-9: a review of their role in breast Cancer risk. Anticancer Res. 2020;40(7):3619-31.

61. Jezierska A, Motyl T. Matrix metalloproteinase-2 involvement in breast cancer progression: a mini-review. Med Sci Monit. 2009;15(2):RA32-40

62. Brown GT, Murray Gl. Current mechanistic insights into the roles of matrix metalloproteinases in tumour invasion and metastasis. J Pathol. 2015;237(3): 273-81.

63. Darlix A, Lamy PJ, Lopez-Crapez E, Braccini AL, Firmin N, Romieu G, Thezenas S, Jacot W. Serum NSE, MMP-9 and HER2 extracellular domain are associated with brain metastases in metastatic breast cancer patients: predictive biomarkers for brain metastases? Int J Cancer. 2016;139(10):2299-311.

64. Kuvaja P, Talvensaari-Mattila A, Paakko P, Turpeenniemi-Hujanen T. Low serum level of pro-matrix metalloproteinase 2 correlates with aggressive behavior in breast carcinoma. Hum Pathol. 2006;37(10):1316-23.

65. Talvensaari-Mattila A, Turpeenniemi-Hujanen T. Preoperative serum MMP-9 immunoreactive protein is a prognostic indicator for relapse-free survival in breast carcinoma. Cancer Lett. 2005;217(2):237-42.

66. Leppa S, Saarto T, Vehmanen L, Blomqvist C, Elomaa I. A high serum matrix metalloproteinase-2 level is associated with an adverse prognosis in nodepositive breast carcinoma. Clin Cancer Res. 2004;10(3):1057-63.

67. Stamenkovic I. Extracellular matrix remodelling: the role of matrix metalloproteinases. J Pathol. 2003;200(4):448-64.

68. Zucker S, Cao J, Chen WT. Critical appraisal of the use of matrix metalloproteinase inhibitors in cancer treatment. Oncogene. 2000;19(56):6642-50.

69. Stuelten $\mathrm{CH}$, DaCosta BS, Arany PR, Karpova TS, Stetler-Stevenson WG, Roberts AB. Breast cancer cells induce stromal fibroblasts to express MMP-9 via secretion of TNF-alpha and TGF-beta. J Cell Sci. 2005;118(Pt 10):2143-53.

70. Singer CF, Kronsteiner N, Marton E, Kubista M, Cullen KJ, Hirtenlehner K, Seifert M, Kubista E. MMP-2 and MMP-9 expression in breast cancer-derived human fibroblasts is differentially regulated by stromal-epithelial interactions. Breast Cancer Res Treat. 2002;72(1):69-77.

71. Li Cl, Uribe DJ, Daling JR. Clinical characteristics of different histologic types of breast cancer. Br J Cancer. 2005;93(9):1046-52.

72. Kreike B, van Kouwenhove $M$, Horlings $H$, Weigelt B, Peterse $H$, Bartelink $H$, van de Vijver MJ. Gene expression profiling and histopathological characterization of triple-negative/basal-like breast carcinomas. Breast Cancer Res. 2007;9(5):R65.

\section{Publisher's Note}

Springer Nature remains neutral with regard to jurisdictional claims in published maps and institutional affiliations. 